\title{
Product functions: interfaces with ergonomic design
}

\author{
Lívia F. de A. Campos ${ }^{\mathrm{a}}$, Jamille N. de L. Lanutti ${ }^{\mathrm{a}}$ and Luis Carlos Paschoarelli ${ }^{\mathrm{a}}$ \\ ${ }^{a}$ PPGDesign, Fac. of Architecture, Arts and Communication, UNESP - Univ Estadual Paulista, Av. Eng. Luis E. \\ C. Coube, 14-01, 17033-360, Bauru, Brazil
}

\begin{abstract}
In addition to technical quality, increasing emphasis is being placed on the importance of elements such as the appearance and meaning of products. To be successful, therefore, attention must be paid to the aesthetic and symbolic functions of objects as well as to reliability and physical quality. Study of the interfaces of these functions may provide a theoretical basis for the ergonomic design of products. The objective of this review is to attempt to establish the nature of these interfaces.
\end{abstract}

Keywords: ergonomic design, emotion, practical function, aesthetic function, symbolic function.

\section{Introduction}

User experience consists of the effects caused by the interaction between a consumer and a product, including the degree to which the senses are gratified (aesthetics), the meaning given to the product (symbolic), and the feelings and emotions engendered (emotional) [7].

It has been argued that “(...) user product rejection is not necessarily connected to problems with complexity or inefficiency" [5]. Thus, it can be hypothesized that there are many more variables associated with the object-user relationship than mere usefulness.

To Mont'Alvão and Damázio [4], the understanding that a product includes much more than physical form and mechanical function has been gaining consistency. Efforts have been made to expand the scope of ergonomic research in order to include emotional aspects of design. However, in spite of advances, there is still no scientific and theoretical basis for organizing and generalizing ideas and relating concepts.

Design theory concepts are required for this approach in that they define a product by its practical, aesthetic and symbolic functions [2]; however, when a product's user experience is analyzed, these functions are presented individually and, according to
Löbach [2], have only been partially studied up to this moment.

The question can be raised whether these functions must necessarily be presented individually in the study of product user experience, as they are dealt with in design theory, or whether a set of overlapping points can provide a theoretical basis for the ergonomic design of products?

By reviewing extant literature, the objective of this paper is to investigate the existence of relationships between product functions, considering them as a theoretical basis for the ergonomic design of objects so as to not only satisfy practical functioning but perceptive demands as well. Such an approach entails the perception of these relationships as a broad possibility for identifying the components necessary to maximize product usefulness, efficacy, acceptability, comfort, and durability.

\section{Review}

"The essential aspects of user relations with industrial products are product functions, which are perceived during use and which satisfy certain needs" [2]. However, every product can have different functions, which can be schematically classified as aesthetic function, symbolic function, and practical function.

\footnotetext{
*Corresponding author. Tel. no. +55 14 31056057. Email: liviaflavia@gmail.com.
} 


\subsection{Aesthetic function}

According to Löbach [2], aesthetic function is an element of the user-object relation on the level of sensory processes. Thus, we can define the aesthetic function of products as "a psychological aspect of sensory perception during use".

Expanding this concept, Bürdek [1] affirms that aesthetic function "encompasses the relationship between the product and the user regarding the sensory perception of formal characteristics, without necessarily observing its meaning."

According to Heufler [6], a product's aesthetic function can be analyzed according to the following formal elements:

- Form: associations regarding product size (large/small), direction (horizontal/vertical/diagonal), lines "straight/curved - geometric/organic) and proportion (golden mean/modular system);

- Material: sensory impressions caused by the use of a certain material (e.g., wood - warmth, metal cold), adequacy between material and product function;

- Surface: associations regarding type of finish visual, tactile (e.g., glossy, matte, smooth, wrinkled, rough, etc.);

- Color: effects of product colors on user reactions (e.g., excitement, tension, boredom, calmness, etc.).

\subsection{Symbolic function}

An object has a symbolic function when "the spirituality of man is stimulated by perceiving this object in connection with previous experiences and sensations". Thus, it can be said that the symbolic function of products is determined by all the spiritual, psychological and social aspects of its use [2].

This function is difficult to establish "since there is no 'Vocabulary of Meanings' for products". Symbolic meanings can be interpreted only by sociocultural contexts, and end up acting as background information that represents the different contexts of the product [1].

Regarding a possible system of classification, Heufler [6] divides the effects of symbolism present in products into three levels:

- Cultural (relevance): the influence of cultural aspects such as the cultural connotations of colors, forms, functions, needs, markings, etc.,

- Social (status): influence from symbolizing or simulating an ideal status. The need for acceptance in a social group and a feeling of security - status symbols, objects of prestige and imitation,
- Personal (emotional): individual associations based on personal experience - personal habits and customs, identification with products, personalization.

\subsection{Practical function}

Practical function is related to the user-product relation on an organic-corporal and physiological level. All physiological aspects of use relate to practical product functions [2].

Bürdek [1] asserts that practical function involves technical functions connected with the handling and manipulation of a product, indicating how it should be utilized. Thus, users should be involved in its development by both contextualizing the function and sharing their experiences.

A system of classification established by Facca [3] states that practical functions may be divided into:

- Informational functions: the visual programming of product identification such as name, brand, logo, instructions, icons, symbols, etc.

- Ergonomic functions: aspects essential for product-user interface, related to the product's method of use and operability, which can be analyzed by means of:

- Usability: the product's ease and convenience of use regarding accessibility, aesthetic effects, adequacy, prevention and correction of errors, feedback, consistency, reduction, flexibility, mapping, mimesis, proximity, compatibility.

- Handling: the form of "coupling" occurring between user and product, through which command movements may be transmitted. This involves study of strength, precision, handling characteristics, grip design, surface finish, the actions involved, etc.

- Comfort: conditions of convenience, well-being and safety perceived by the user on physical, physiological and psychological levels;

- Universality: product characteristics that allow it to be used by most people, i.e., principles of equitable use, flexibility, simple and intuitive use, vivible information, tolerance to error, reduction of energy expenditure;

- Anthropometric adaptation: the user-product dimensional relationship, which is fine-tuned by defining project requirements, important dimensions, target audience, the percentile of this audience to be served and the relationship with relevant anthropometric measurements.

- Postures: body postures and their consequences: stress, pain, fatigue. 


\section{Discussion}

In the literature investigated, it was observed that design theory does not present direct relations between the various product functions. However, relationship were observed to exist between two and even three product functions.

\subsection{Aesthetic vs. Symbolic Function}

Both aesthetic and symbolic functions occur on the level of sensory processes, and both contribute to user appreciation.

The elements related to "Sensory Processes", "Appreciation" and "Configurations" are elements common to these two functions, and influence them both (Figure 1).

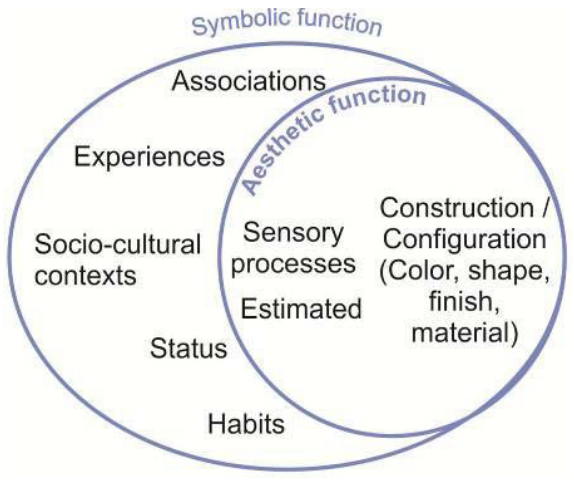

Fig 1

Relation between symbolic and aesthetic functions

This suggests that aesthetics can be evaluated based on the meanings established by the subjects, as well as by the meaning embedded in a product's aesthetic configuration.

\subsection{Aesthetic Function vs. Practical Function}

Regarding the relationship between aesthetic and practical functions, both are based on the configuration of the product as an interface. It is through this interface that the individual utilizes the product (Figure 2).

The inference to be drawn from this observation is that an object's aesthetic elements serve as support for the configurations of practical function, i.e., product usability.
This finding makes it possible to hypothesize that the aesthetics of a product may interfere in the object's ease or difficulty of use.

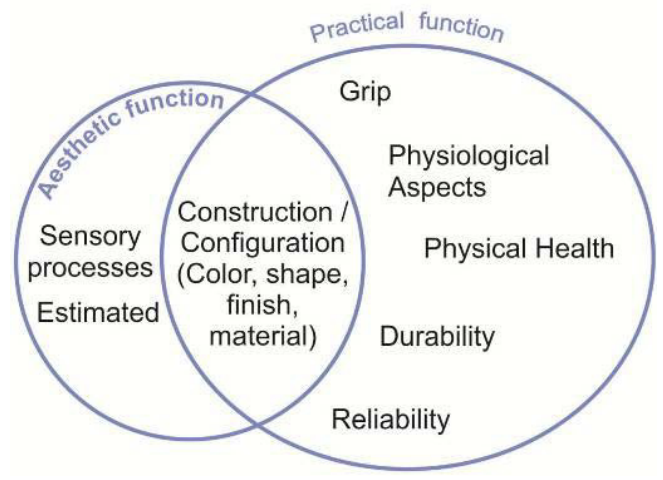

Fig 2

Relations between aesthetic and practical functions.

\subsection{Symbolic Function vs. Practical Function}

The symbolic and practical functions also include elements of product configuration as interface elements. This suggests, as in aesthetic function, that the characteristics of an object's construction (color, form, finish and material) support the object's symbolic aspects and can theoretically interfere in its use.

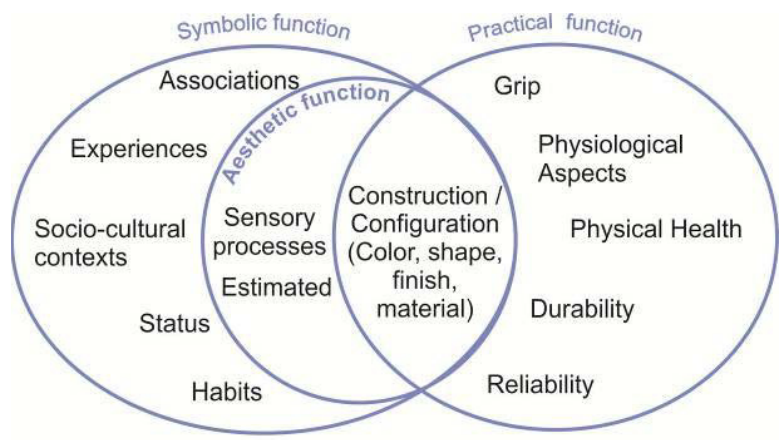

Fig 3

Relations between symbolic and practical functions.

\subsection{Symbolic Function vs. Aesthetic Function vs. Practical Function}

Finally, it is inferred that the interface between the three functions is fundamentally supported by the configuration of the object, which carries in its appearance (aesthetic function) the meanings of the product (symbolic function) and can, hypothetically, 
interfere in aspects of use (practical function) (Figure 4).

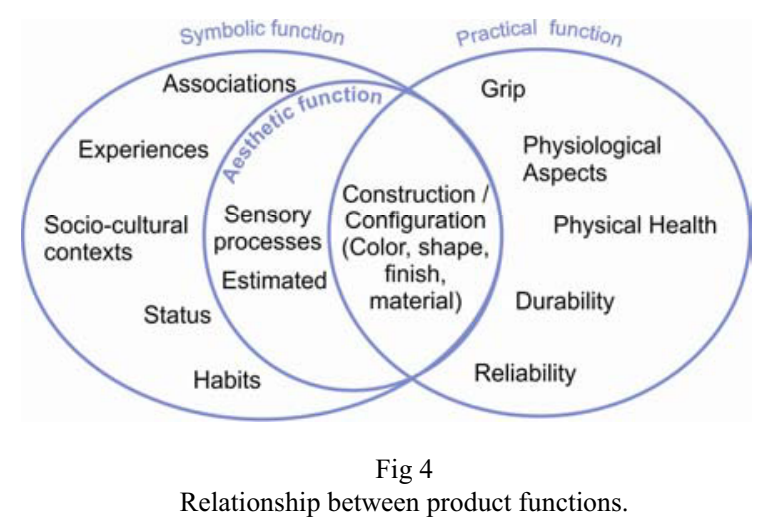

\section{Final Considerations}

An analysis of use that considers (1) the configuration of elements (material, finish, color, forms, etc.) in the three function planes, (2) the relationship between these planes, and (3) the influence of these elements on the other components of each function may lead to new methods of ergonomic product development in which configuration is considered as the principle means of maximizing use.

There is a need for future studies seeking to understand the influence of a product's meaning and aesthetics on its ease of use, that is, on its "full" usability.

\section{Acknowledgements}

This study was supported by FAPESP - São Paulo Research Foundation (Proc. 2010/20439-9); CNPQ National Council for Scientific and Technological Development (Proc. 303138/2010-6).

\section{References}

[1] B.E.Bürdek, Design History, Theory and Practice of Product Design. Edgard Blücher, ed., São Paulo, 2006, p.496. [in portuguese]

[2] B. Löbach, Industrial Design: basis for the configuration of industrial products. Edgard Blücher, ed., São Paulo, 2001, p.206. [in portuguese]

[3] C.A. Facca. Design History, theory and practice of product Design. Master in Design, University Anhembi Morumbi, São Paulo, 2008, p.213. [in portuguese]

[4] C. Mont'alvão and V. Damázio (Orgs.) Design Ergonomics Emotion. Mauad X:FAPERJ, ed., Rio de Janeiro, 2008, p.128. [in portuguese]

[5] C.R.P.X. Medeiros and M.L.L.R. Okimoto, Cockpit trucks to transport cargo, ergonomic and usability from the point of view of the driver end user, in: Proceedings of the 14th Brazilian Congress on Ergonomics-Abergo, Recife, 2006. [in portuguese]

[6] G. Heufler. Design basics from ideas to products. Verlag Niggli AG, ed., Zurich, 2004, p.191.

[7] P. Hekkert. Design aesthetics: principiles of pleasure in design. Psychology Science, 48, 2006, p. 157-172. 